\title{
The Use of Point-of-Care Ultrasound in Acute Kidney Injuries
}

\author{
Kristin N. Sheehan, Christopher T. Kelly \\ Department of Internal Medicine, Wake Forest School of Medicine, Winston-Salem, NC, USA \\ Email: knsheeha@wakehealth.edu
}

How to cite this paper: Sheehan, K.N. and Kelly, C.T. (2022) The Use of Point-of-Care Ultrasound in Acute Kidney Injuries. Open Journal of Internal Medicine, 12, 1-12. https://doi.org/10.4236/ojim.2022.121001

Received: November 22, 2021

Accepted: January 23, 2022

Published: January 26, 2022

Copyright $\odot 2022$ by author(s) and Scientific Research Publishing Inc. This work is licensed under the Creative Commons Attribution International License (CC BY 4.0).

http://creativecommons.org/licenses/by/4.0/

\begin{abstract}
Acute kidney injuries (AKI) are a common problem encountered by internists in the inpatient and outpatient setting. Uncovering the etiology becomes important in tailoring treatment. Point-of-care ultrasound (POCUS), when used in conjunction with a patient's history and physical exam, can quickly identify if hydronephrosis is present and shed light on the underlying etiology. In this article, we discuss how incorporating POCUS into the initial assessment of patients with an AKI can reduce the number of unnecessary and expensive formal renal ultrasounds and potentially expedite clinically appropriate treatment. The purpose of this review is to examine the benefits, reliability, and feasibility of POCUS to further evaluate and manage patients with AKI. An extensive review of the literature was performed and found POCUS to be a reliable and realistic method for internists to incorporate into their assessment of patients with AKI. In this article, we also provide instruction on how to perform a POCUS exam of the kidneys and how to identify hydronephrosis. Furthermore, we discuss the challenges we face and ideas for further practice including the emergence of hand-held ultrasounds.
\end{abstract}

\section{Keywords}

POCUS, Acute Kidney Injury, Renal Ultrasound, Hydronephrosis

\section{Introduction}

Acute kidney injury (AKI) is defined by the Kidney Disease Improving Global Outcomes (KDIGO) as a rise in serum creatinine by at least $0.3 \mathrm{mg} / \mathrm{dl}$ above the baseline within $48 \mathrm{hrs}$, an increase in creatinine by at least $1.5 \times$ baseline presumed to have occurred within the prior 7 days, or urine output of $0.5 \mathrm{ml} / \mathrm{kg} / \mathrm{h}$ or less for 6 hours [1]. Of all hospitalized patients, 5\% - 78\% will either present with, or develop, an AKI during their hospital course, making diagnosis and management of 
AKI a common and crucial component of every internist's practice [2] [3]. Additionally, the presence of an acute kidney injury significantly increases patient mortality and costs healthcare systems billions of dollars each year [4]. Historically, some providers reflexively order a formal, radiologist-read renal ultrasound as part of the initial work-up for all patients with acute kidney injuries. Naturally this led to an abundance of unnecessary and costly imaging tests [5] [6] [7] [8]. One study looked retrospectively at renal ultrasounds performed at a university hospital in Texas over a three-year period [9]. They found that 1471 renal ultrasounds were performed, of which, 55\% were for the evaluation of AKI. Ultrasound findings were normal in $62 \%$ of those imaged and hydronephrosis was only detected in 5\%. Therefore, it was concluded that many formal ultrasounds were unnecessary. There is also a significant amount of time between when the provider places the renal ultrasound order to when a sonographer performs the exam, and then the radiologist reading it releases a report. This can potentially lead to a substantial delay in initiation of appropriate treatment.

There are a vast number of hospitalized patients who are treated for acute renal injuries and limiting unnecessary imaging in this population can make a huge difference in regards to healthcare costs and utilization of hospital resources. With the emergence of point-of-care ultrasound (POCUS) and the recent push for its incorporation into the field of Internal Medicine, we propose that POCUS can be a useful tool to extend the physical exam during the initial assessment of patients with an AKI.

This review aims to first examine the benefits of using POCUS in patients with AKI, focusing on reduction in unnecessary formal renal ultrasounds performed and a quicker initiation of appropriate treatment. We determine whether the use of POCUS by the internist is reliable, practical, and can be reasonably incorporated into current practice. An extensive literature review was performed on this subject. Table 1 highlights a selection of relevant studies specifically looking at the use of POCUS in AKI (Table 1). Additionally, we provide a how-to section for performing renal POCUS and identifying hydronephrosis. Finally, we close with a discussion of the current challenges in this field and ideas for future practice.

\section{Incorporating POCUS into Clinical Reasoning}

The causes of AKIs are plentiful and are often divided into groups based on origin: pre-renal, intra-renal, and post-renal [10] [11] [12] [13]. Typically, providers focus on a patient's history, calculation of fractional excretion of sodium (or fractional excretion of urea), and a trial of fluids as a way to initially classify the injury. If a post-renal etiology is on the differential, then a formal renal US may be ordered. However, completing this imaging test and receiving the final report can take hours to days depending on the clinical setting and day of the week, which can result in a delay in diagnosis.

The incorporation of POCUS as an extension of the physical exam can be 
Table 1. A selection of literature that highlights the use of POCUS in AKI.

\begin{tabular}{|c|c|c|}
\hline Title & Type & Summary \\
\hline $\begin{array}{l}\text { Clinical utility of gray scale } \\
\text { renal ultrasound in acute } \\
\text { kidney injury [9] }\end{array}$ & $\begin{array}{l}\text { Retrospective } \\
\text { cohort }\end{array}$ & $\begin{array}{l}\text { Looked at } 1471 \text { renal US, of which } 55 \% \\
\text { were for evaluation of AKI. Results } \\
\text { were normal in } 62 \% \text { and } \\
\text { hydronephrosis detected in only } 5 \% \text {. } \\
\text { Concluded that renal US for evaluation } \\
\text { of AKI is indicated only if there if } \\
\text { history suggestive of obstruction. }\end{array}$ \\
\hline $\begin{array}{l}\text { Point-of-care ultrasound } \\
\text { rapidly and reliably } \\
\text { diagnoses renal tract } \\
\text { obstruction in patients } \\
\text { admitted with acute } \\
\text { kidney injury [14] }\end{array}$ & $\begin{array}{l}\text { Prospective } \\
\text { observational }\end{array}$ & $\begin{array}{l}\text { In patients with AKI, looked at using } \\
\text { POCUS first to identify } \\
\text { hydronephrosis. Found it was very } \\
\text { accurate, saved time, required little } \\
\text { training, and could be utilized } \\
\text { by IM doctors. }\end{array}$ \\
\hline $\begin{array}{l}\text { Quantifying systemic } \\
\text { congestion with } \\
\text { point-of-care ultrasound: } \\
\text { development of the venous } \\
\text { excess ultrasound grading } \\
\text { system [15] }\end{array}$ & $\begin{array}{l}\text { Post-hoc } \\
\text { analysis of a } \\
\text { single-center } \\
\text { prospective } \\
\text { study }\end{array}$ & $\begin{array}{l}\text { Tested invention of a venous } \\
\text { grading system to assess vasculature } \\
\text { of the kidney in patients with AKI. }\end{array}$ \\
\hline $\begin{array}{l}\text { Simplified approach for } \\
\text { the assessment of kidney } \\
\text { perfusion and acute kidney } \\
\text { injury at the bedside using } \\
\text { contrast-enhanced } \\
\text { ultrasound [16] }\end{array}$ & $\begin{array}{l}\text { Letter to } \\
\text { the editor }\end{array}$ & $\begin{array}{l}\text { Discussed using contrast-enhanced } \\
\text { US to assess microvasculature. Found } \\
\text { that patients with renal injury had } \\
\text { higher contrast inflow time. }\end{array}$ \\
\hline $\begin{array}{l}\text { The role of point-of-care } \\
\text { ultrasound monitoring in } \\
\text { cardiac surgical patients } \\
\text { with acute kidney injury } \\
\text { [17] }\end{array}$ & $\begin{array}{l}\text { Review } \\
\text { article }\end{array}$ & $\begin{array}{l}\text { Discusses the role of POCUS in AKI, } \\
\text { including hydronephrosis and renal } \\
\text { resistive indexes of renal vessels. }\end{array}$ \\
\hline $\begin{array}{l}\text { Ultrasound assessment of } \\
\text { acute kidney injury [7] }\end{array}$ & $\begin{array}{l}\text { Review } \\
\text { article }\end{array}$ & $\begin{array}{l}\text { Describes US findings in AKI from a } \\
\text { radiologist's point-of-view. }\end{array}$ \\
\hline $\begin{array}{l}\text { Reducing unnecessary } \\
\text { testing: ultrasound in acute } \\
\text { kidney injury [8] }\end{array}$ & Letter/QI & $\begin{array}{l}\text { Describes a QI project to reduce } \\
\text { number of renal US's ordered. } \\
\text { Intervention was education on utility. } \\
\text { Result was less US orders and all } \\
\text { orders now justified. }\end{array}$ \\
\hline
\end{tabular}

useful in making an immediate initial assessment of a patient. This can help minimize the time spent with diagnostic uncertainty, leading to faster diagnosis and quicker initiation of the correct management. For example, Novaes et al. present a case in which an infraumbilical lump prompted a POCUS exam which revealed evidence of long-term obstruction by the presence of a distended bladder, large bladder diverticulum, and bilateral hydronephrosis [18]. The POCUS 
findings led to quick action with urinary catheter placement to relieve the obstruction.

We propose that using POCUS to extend the physical exam during the initial assessment of patients with an AKI can be incorporated into your clinical reasoning to help uncover the underlying etiology and determine if a formal, radiologist-read, renal ultrasound is truly needed (Figure 1). If after history, physical exam, and renal POCUS, there is high confidence (low pretest probability) that hydronephrosis is not present, additional work-up and treatment targeted towards pre-renal and intrarenal causes should be pursued. Similarly, if there if high confidence that hydronephrosis is present (high pretest probability), immediate intervention including urinary catheter placement, can be initiated. In cases where confidence levels are low with respect to the POCUS findings or if there are incidental or unexpected findings, then formal renal ultrasound or another imaging modality could be considered if clinically indicated. Using this method of stratification, patients who have the potential to benefit the most from renal ultrasound will be selected, and unnecessary orders will be minimized.

\section{Accuracy}

For renal POCUS to be a useful adjunct, it must be accurate in its ability to predict pathology. Throughout the literature the use of POCUS by physicians has been shown in medical literature to be a relatively accurate means to identify hydronephrosis. A prospective observational study by Nepal, Dachsel, and Smallwood took physicians with varying amounts of training in a POCUS

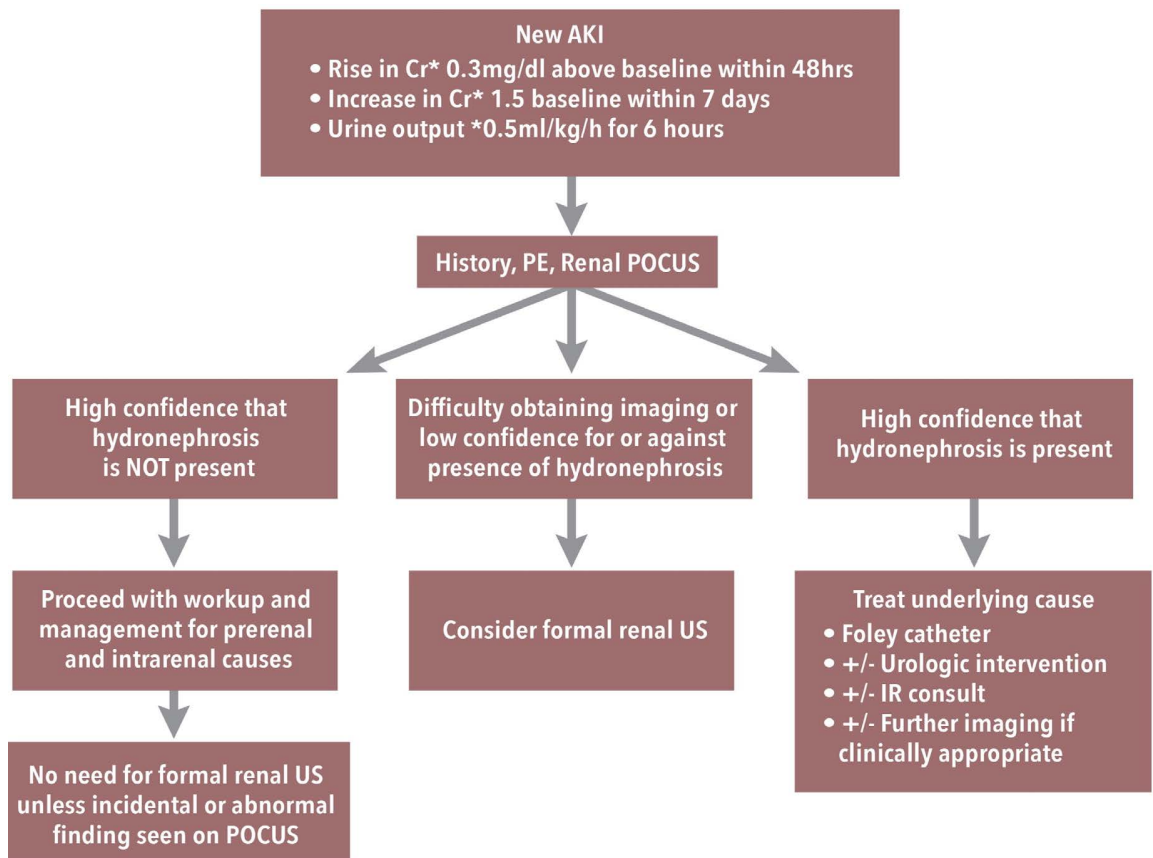

Figure 1. A proposed decision tree demonstrating how POCUS can be incorporated into the initial evaluation of patients with AKI. 
curriculum and measured their ability to detect hydronephrosis in patients with AKI [14]. When compared to formal renal US or CT scan, they found that accurate identification of the presence or absence of hydronephrosis occurred in 95 out of 96 cases (sensitivity of $90 \%$, specificity of $100 \%$, positive predictive value of $100 \%$ and a $99 \%$ negative predictive valve). These results suggest that POCUS is an acceptable alternative to formal renal ultrasound. This point was again demonstrated by Pathan, et al. who looked at the accuracy of emergency room physicians' ability to identify and grade severity of hydronephrosis of POCUS images when compared to radiologists' interpretation and CT findings [19]. Presence or absence of hydronephrosis was agreeable between emergency physicians and radiologists with a sensitivity of $85.7 \%$ and a specificity of $65.9 \%$. These values were slightly lower when CT comparison was used. However, when stratified by severity, consensus between emergency physicians and CT scans was found to have a specificity of $94.6 \%$ for detection of moderate or severe hydronephrosis. Thus, in moderate to severe disease states, POCUS can reliably be used to rule-in hydronephrosis. Another study looking at POCUS accuracy compared emergency room residents and attendings vs. CT imaging or ultrasound read by radiologists [20]. Participating physicians completed any kind of formal ultrasound training course prior to the study. The detection of hydronephrosis was the primary outcome. Results showed a sensitivity of $77.1 \%$ and specificity of $71.8 \%$ which improved with higher degrees of hydronephrosis. Authors concluded that POCUS was not adequate as a "stand-alone diagnostic tool," but may help predict those patients who require further imaging. Overall, the ability for providers to detect hydronephrosis, especially severe hydronephrosis, has been shown to be highly accurate and a reliable means to guide clinical decision making.

\section{Skill Acquisition}

In order for renal POCUS to be reasonably incorporated into current practice the skills required to perform the imaging must be attainable with little additional training. Adequate POCUS skills can be acquired by general physicians through short training courses. With recent pushes to incorporate ultrasound training into residencies and medical school curriculums, numerous studies, including those by Javaudin et al., show that with relatively little training, physicians can accurately identify hydronephrosis [21]. In this prospective observational study, six physicians were given a 16-hour training session over the course of two days and were then assessed on their ability to detect hydronephrosis on POCUS. Overall, 50 ultrasounds were performed and identification of hydronephrosis had a sensitivity and a negative predictive value of $100 \%$. A similar study also employed a 16-hour training course in which 9 residents took part [22]. They were trained in a variety of aspects of POCUS including heart, lung, vascular, and renal exams. Success was gaged with pre- and post-course assessments. Average scores increased from $11 / 20$ to $15 / 20$ on post-course multiple choice questions and from $6 / 10$ to $9 / 10$ on post-course image association ques- 
tions. These studies tell us that learning how to perform POCUS and integrating POCUS into clinical practice is feasible for the internist.

\section{The Role of Renal POCUS for the Internist}

The emergence of POUCS has become a great tool for the internist. Acute kidney injuries are managed in almost every medical setting, including a large portion on inpatient medicine services. It has been shown that the proficient use of POCUS can be achieved with relatively short training periods, which makes it a realistic skill to incorporate into internal medicine training. Currently the use of POCUS in many hospitals remains within the emergency room setting, as its use there has been historically emphasized. This explains why the vast majority of the cited references occurred in the emergency room setting. POCUS is a newer skill set for Internal Medicine providers.

The literature names many possible renal uses for bedside ultrasound, including use as an aid in differentiating AKI etiologies, assessing renal vasculature, and identifying obstructing stones [15] [16] [17] [23] [24] [25] [26] [27] [28] [29]. Here we focus on its utility in identifying hydronephrosis. This can be helpful in both the inpatient and outpatient settings. In the inpatient setting, a POCUS exam can be performed at any point during a patient's hospital stay, and Internal Medicine providers typically have continuity with their patients. POCUS exams performed during the initial assessment can aid in the diagnostic process and management decisions, and serial POCUS exams on subsequent days can be used to assess response to treatment and/or assist with rethinking a particular diagnosis.

\section{Using POCUS to Detect Hydronephrosis}

The kidneys are located in the retroperitoneum with the left kidney lying slightly more superior and posterior compared to the right (Figure 2). Each one is composed of the cortex, medullary pyramids, renal sinus, and the ureter. Blood is filtered at the glomerulus located in the cortex. Filtrate then moves through the proximal convoluted tubules, loop of Henle, distal convoluted tubules, and collecting duct, moving from the cortex to the pyramids, and then into the renal sinus and out into the ureter [30] [31]. On ultrasound imaging, the cortex forms the outline of the kidney, as shown below (Figure 2). In a normal kidney, the medullary pyramids are the hypoechoic regions within the kidney boundaries, and the renal sinus appears as the most hyperechoic region within the middle of the kidney.

Post-renal causes of acute kidney injuries include pathologies that obstruct the ureters, bladder outlet, or urethra, leading to a back-up in pressure and distension of the renal system. Most common etiologies are benign prostatic hypertrophy and nephrolithiasis, followed by other causes including neurogenic bladder, retroperitoneal fibrosis, crystals, clots, and tumors [32] [33] [34]. When obstruction is great enough to cause AKI, hydronephrosis of one or both kidneys may be seen. 


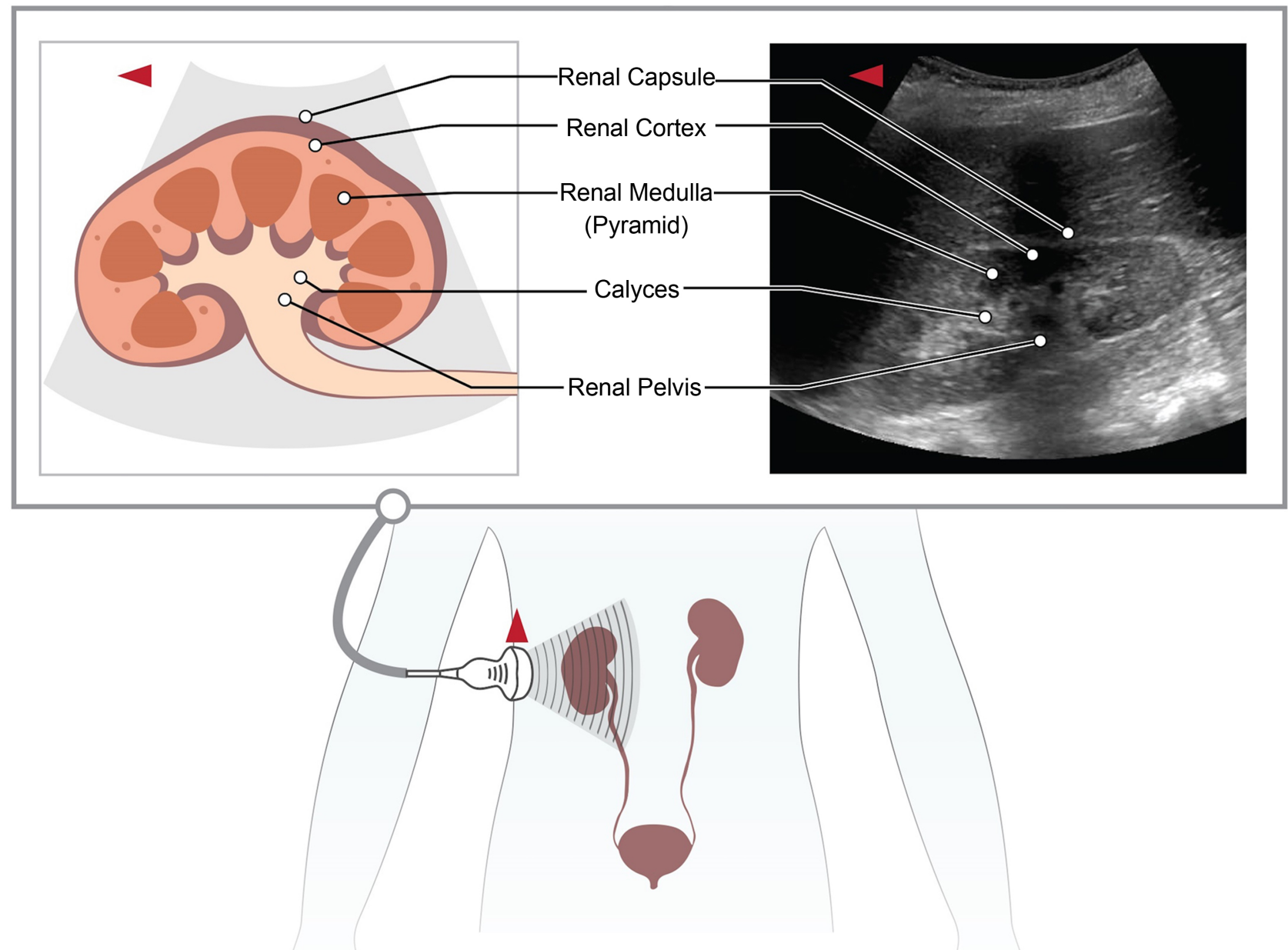

Figure 2. Scanning technique and kidney anatomy. A visual representation of an ultrasound scan of the right kidney in longitudinal view, along with images demonstrating important anatomic structures of the kidney.

To obtain a view of the kidney using POCUS, begin by selecting a low frequency probe (curvilinear or phased array) and set it to the abdominal preset [35]. First obtain a longitudinal view of the right kidney [36]. With the probe indicator pointing up towards the patient's head, place the probe on the right flank. Use the bottom of the sternum and the mid-axillary line to guide initial probe placement. Slide the probe inferiorly as needed to locate the right kidney, then fan through from the anterior edge to the posterior edge to assess the kidney in its entirety. Next, rotate the probe 90 degrees counterclockwise so the probe marker faces towards the patient's right to obtain a transverse (short axis) view of the kidney. Fan through from superior pole to inferior pole to assess for abnormalities. The same can be done to assess the left kidney. For the left side, begin by placing the probe at the level of the bottom of the sternum in the posterior axillary line. Slide the probe inferiorly as needed to locate the kidney, then fan through from the anterior edge to the posterior edge. Rotate the probe 90 degrees counterclockwise to obtain the transverse view, fan from the superior pole to the inferior pole. 
The presence of hydronephrosis in either kidney can be detected as distorted architecture and an increase in hypoechoic regions within the renal sinus (Figure 3). Grading of mild, moderate, and severe hydronephrosis is determined by the extent of structure dilation. Several grading systems have been established but there has been no consistent consensus on their use [37]. In general, disease states progress from dilation of the ureter and renal pelvis to the major calyces, then minor calyces, and finally to dilation and thinning of the renal cortex. In mild hydronephrosis, there is dilation of only the renal pelvis and calyces [38]. Progression to moderate hydronephrosis means the pressure build-up is now causing flattening of the medullary pyramids and outpouching of the calyces. In severe hydronephrosis, the differentiation between cortex and medulla is lost and the cortex thins (Table 2).

\section{Limitations}

While POCUS use by internists has been of great interest recently, some practical drawbacks still exist. First, new learners must have the opportunity to receive
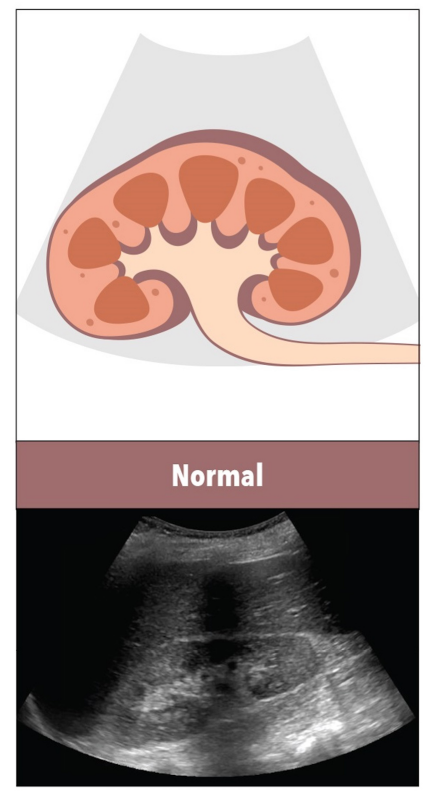
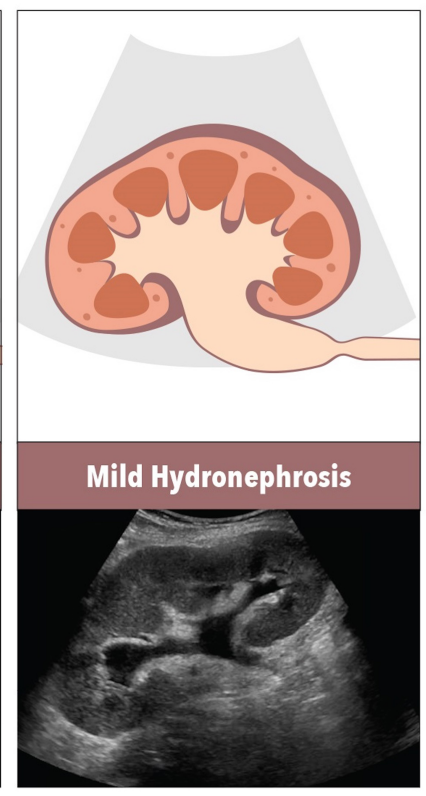
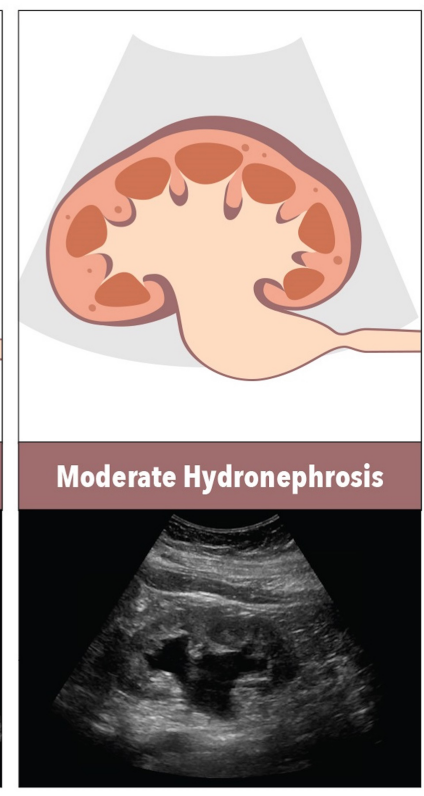

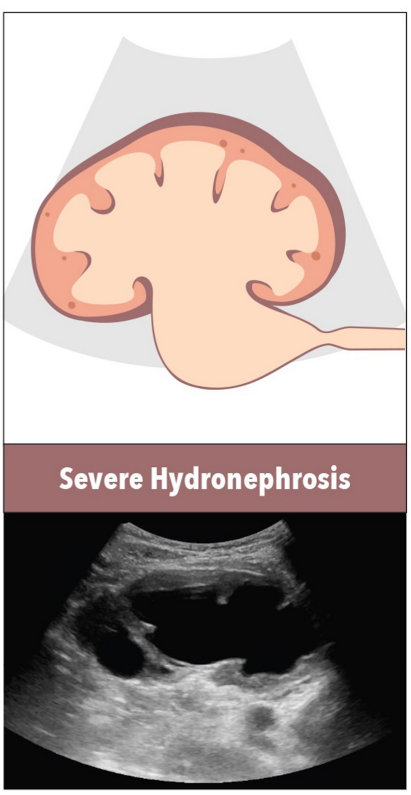

Figure 3. Progression of hydronephrosis. Visual representation of a normal kidney compared to mild, moderate, and severe hydronephrosis as shown on ultrasound with corresponding architectural changes of the kidney.

Table 2. Description of changes seen in the kidney at each stage of hydronephrosis.

\begin{tabular}{cl}
\hline Degree of hydronephrosis & \multicolumn{1}{c}{ Description of changes to kidney architecture } \\
\hline Mild & - Dilation of the renal pelvis \\
& - Dilation of the calyces \\
Moderate & - Flattening of the medullary pyramids \\
& - Outpouching of the calyces \\
Severe & - Thin cortex \\
& - Loss of differentiation between cortex and medulla
\end{tabular}


training. This necessitates having supervising physicians who are trained, willing, and motivated to teach new learners. While current studies focus solely on initial training sessions, further studies are needed to determine optimal interval follow-up periods for maximal retention of newly learned POCUS skills.

Second, in many hospitals access to POCUS technology and equipment remains a large barrier to its use. Ultrasound machines are expensive and may be difficult for smaller hospitals or ones with lower budgets to obtain. In larger hospitals with only one or two machines, the extra time it takes to retrieve the ultrasound may pose as a barrier to routine use. Additionally, although POCUS exams should ideally only take a couple extra minutes, this may add up to a significant time burden for physicians with high patient loads. These are some of the challenges that will need to be overcome before POCUS can become a universal part of the internist's workflow.

\section{Looking to the Future}

Despite the current challenges of incorporating POCUS into the Internal Medicine world, new technology may help reduce or eliminate some of these barriers. One such example is the emergence of hand-held ultrasounds. The current literature regarding the use of and accuracy of hand-held ultrasounds is relatively limited given the novelty of the subject. However, for a general internist looking for gross abnormalities, a hand-held ultrasound should be sufficient. Several early studies have demonstrated their accuracy in cardiac and liver exams [39] [40] [41] [42]. Hand-held machines would make the use of ultrasound more portable, thus making them more available and decreasing overall time burden associated with exam performance. Additionally, the cost of equipment is decreasing. The hope is that more hospitals will be able to afford ultrasounds, therefore giving more physicians the opportunity to learn and enhance the skills needed to confidently incorporate POCUS exams into the inpatient setting.

\section{Conclusion}

Overall, the current literature regarding the use of POCUS in AKI is overwhelmingly positive. POCUS has been shown to be accurate in detecting hydronephrosis and adequate skills can be obtained with relatively short training periods. The literature supports the conclusion that internists can reliably use POCUS alongside their history and physical exam to aid in diagnosis and act as a means to identify those patients who will benefit most from more formal imaging, thus preserving healthcare resources and cost. Overall, the use of POCUS is an accurate, timely, feasible, and realistic method for internists to incorporate into their assessment of patients with an AKI in an effort to expedite treatment, improve patient care, and reduce the number of unnecessary formal imaging tests.

\section{Conflicts of Interest}

The authors declare no conflicts of interest regarding the publication of this paper. 


\section{References}

[1] Khwaja, A. (2012) KDIGO Clinical Practice Guidelines for Acute Kidney Injury. Nephron Clinical Practice, 120, c179-c184. https://doi.org/10.1159/000339789

[2] Negi, S., Koreeda, D., Kobayashi, S., Yano, T., Tatsuta, K., Mima, T., et al. (2018) Acute Kidney Injury: Epidemiology, Outcomes, Complications, and Therapeutic strategies. Seminars in Dialysis, 31, 519-527. https://doi.org/10.1111/sdi.12705

[3] Yalavarthy, R. and Edelstein, C.L. (2008) Therapeutic and Predictive Targets of AKI. Clinical Nephrology, 70, 453-463. https://doi.org/10.5414/CNP70453

[4] Chertow, G.M., Burdick, E., Honour, M., Bonventre, J.V. and Bates, D.W. (2005) Acute Kidney Injury, Mortality, Length of Stay, and Costs in Hospitalized Patients. Journal of the American Society of Nephrology, 16, 3365-3370. https://doi.org/10.1681/ASN.2004090740

[5] Flint, N. and Siegel, R.J. (2019) Yes We (S)can! Annals of Internal Medicine, 171, 291-292. https://doi.org/10.7326/M19-1918

[6] Rad, A.H. and Badeli, H. (2017) Point-of-Care Ultrasonography: Is It Time Nephrologists Were Equipped with the 21th Century's Stethoscope? Iranian Journal of Kidney Diseases, 11, 259-262.

[7] Kelahan, L.C., Desser, T.S., Troxell, M.L. and Kamaya, A. (2019) Ultrasound Assessment of Acute Kidney Injury. Ultrasound Quarterly, 35, 173-180. https://doi.org/10.1097/RUQ.0000000000000389

[8] Barakzai, A., Wenzlick, L., Deol, N., Barakzai, S. and Kumar, S. (2018) Reducing Unnecessary Testing: Ultrasound in Acute Kidney Injury. American Journal of Medical Quality, 33, 448. https://doi.org/10.1177/1062860617744046

[9] Podoll, A., Walther, C. and Finkel, K. (2013) Clinical Utility of Gray Scale Renal Ultrasound in Acute Kidney Injury. BMC Nephrology, 14, Article No. 188. https://doi.org/10.1186/1471-2369-14-188

[10] Levey, A.S. and James, M.T. (2017) In the Clinic: Acute Kidney Injury. Annals of Internal Medicine, 167, ITC66-ITC80. https://doi.org/10.7326/AITC201711070

[11] Thind, G., Fox, S., Gupta, M., Chahar, P., Jones, R. and Dugar, S. (2021) Point-of-Care Ultrasonography for the Hospitalist. Cleveland Clinic Journal of Medicine, 88, 345-359. https://doi.org/10.3949/ccjm.88a.20141

[12] Yang, F., Zhang, L., Wu, H., Zou, H. and Du, Y. (2014) Clinical Analysis of Cause, Treatment and Prognosis in Acute Kidney Injury Patients. PLoS ONE, 9, Article ID: e85214. https://doi.org/10.1371/journal.pone.0085214

[13] Mercado, M., Smith, D. and Guard, E. (2019) Acute Kidney Injury: Diagnosis and Management. American Family Physician, 100, 687-694.

[14] Nepal, S., Dachsel, M. and Smallwood, N. (2020) Point-of-Care Ultrasound Rapidly and Reliably Diagnoses Renal Tract Obstruction in Patients Admitted with Acute Kidney Injury. Royal College of Physicians, 20, 541-544. https://doi.org/10.7861/clinmed.2019-0417

[15] Beaubien-Souligny, W., Rola, P., Haycock, K., Bouchard, J., Lamarche, Y., Spiegel, R. and Denault, A.Y. (2020) Quantifying Systemic Congestion with Point-of-Care Ultrasound: Development of the Venous Excess Ultrasound Grading System. The Ultrasound Journal, 12, Article No. 16. https://doi.org/10.1186/s13089-020-00163-w

[16] Gocze, I., Renner, P., Graf, B.M., Schlitt, H.J., Bein, T. and Pfister, K. (2015) Simplified Approach for the Assessment of Kidney Perfusion and Acute Kidney Injury at the Bedside Using Contrast-Enhanced Ultrasound. Intensive Care Medicine, 41, 
362-363. https://doi.org/10.1007/s00134-014-3554-7

[17] Beaubien-Souligny, W., Denault, A., Robillard, P. and Desjardins, G. (2019) The Role of Point-of-Care Ultrasound Monitoring in Cardiac Surgical Patients with Acute Kidney Injury. Journal of Cardiothoracic and Vascular Anesthesia, 33, 2781-2796. https://doi.org/10.1053/j.jvca.2018.11.002

[18] Novaes, A.K.B., Barros do Carmo, W., Avarese de Figueiredo, A., Lopes, P.C., Dias, Z.M.M., Silva, L.A.L. and Bastos, M.G. (2017) Point of Care Kidney Ultrasonography and Its Role in the Diagnosis of Urinary Obstruction: A Case Report. Brazilian Journal of Nephrology, 39, 220-223. https://doi.org/10.5935/0101-2800.20170038

[19] Pathan, S.A., Mitra, B., Mirza, S., Momin, U., Ahmed, Z., Andraous, L., et al. (2018) Emergency Physician Interpretation of Point-of-Care Ultrasound for Identifying And Grading of Hydronephrosis in Renal Colic Compared with Consensus Interpretation by Emergency Radiologists. Society for Academic Emergency Medicine, 25, 1129-1137. https://doi.org/10.1111/acem.13432

[20] Sibley, S., Roth, N., Scott, C., Rang, L., White, H., Sivilotti, M.L.A. and Bruder, E. (2020) Point-of-Care Ultrasound for the Detection of Hydronephrosis in Emergency Department Patients with Suspected Renal Colic. The Ultrasound Journal, 12, Article No. 31. https://doi.org/10.1186/s13089-020-00178-3

[21] Javaudin, F., Mounier, F., Pes, P., Arnaudet, I., Vignaud, F., Frampas, E., et al. (2017) Evaluation of a Short Formation on the Performance of Point-of-Care Renal Ultrasound Performed by Physicians without Previous Ultrasound Skills: Prospective Observational Study. Critical Ultrasound Journal, 9, Article No. 23. https://doi.org/10.1186/s13089-017-0078-8

[22] Nunes, A.A., Pazeli Jr., J.M., Rodrigues, A.T., Tollendal, A.L.S.V., Ezequiel, O.d.S., Colugnati, F.A.B. and Bastos, M.G. (2016) Development of Skills to Utilize Point-of-Care Ultrasonography in Nephrology Practice. Brazilian Journal of Nephrology, 38, 209-214. https://doi.org/10.5935/0101-2800.20160030

[23] Dversdal, R.K., Piro, K.M., LoPresti, C.M., Northcutt, N.M. and Schnobrich, D.J. (2018) Point-of-Care Ultrasound in the Inpatient Setting: A Tale of Four Patients. The Southern Medical Association, 111, 382-388.

[24] Wong, C., Teitge, B., Ross, M., Young, P., Robertson, H.L. and Lang, E. (2018) The Accuracy and Prognostic Value of Point-of-Care Ultrasound for Nephrolithiasis in the Emergency Department: A Systematic Review and Meta-Analysis. Society for Academic Emergency Medicine, 25, 684-698. https://doi.org/10.1111/acem.13388

[25] Soomro, Q.H. and Amerling, R. (2021) Point-of-Care Ultrasound in Nephrology. Current Opinion in Nephrology and Hypertension, 30, 176-183. https://doi.org/10.1097/MNH.0000000000000681

[26] Dalziel, P. and Noble, V. (2013) Bedside Ultrasound and the Assessment of Renal colic: A Review. Emergency Medicine Journal, 30, 3-8. https://doi.org/10.1136/emermed-2012-201375

[27] Leo, M., Langlois, B., Pare, J., Mitchell, P., Linden, J., Nelson, K., et al. (2017) Ultrasound vs. Computed Tomography for Severity of Nephronephrosis and Its Importance in Renal Colic. Western Journal of Emergency Medicine, 18, 559-568. https://doi.org/10.5811/westjem.2017.04.33119

[28] Smallwood, N. and Dachsel, M. (2018) Point-of-Care Ultrasound (POCUS): Unnecessary Gadgetry or Evidence-Based Medicine? Clinical Medicine, 18, 219-224. https://doi.org/10.7861/clinmedicine.18-3-219

[29] Smith-Bindman, R., Aubin, C., Bailitz, J., Bengiamin, R., Camargo, C., Corbo, J., et al. (2014) Ultrasonography versus Computed Tomography for Suspected Nephroli- 
thiasis. The New England Journal of Medicine, 371, 1100-1110. https://doi.org/10.1056/NEJMoa1404446

[30] Johnson, R., Feehally, J. and Floege, J. (2015) Renal Anatomy. In: Johnson, R., Feehally, J. and Floege, J., Eds., Comprehensive Clinical Nephrology, Vol. 5, Elsevier/Saunders, Philadelphia, 2-13.

[31] Fogo, A., Bruijn, J., Cohen, A., Colvin, R. and Jennette, J. (2006) Fundamentals of Renal Pathology. Springer, New York, 3-19. https://doi.org/10.1007/978-0-387-31127-2

[32] Rahman, M., Shad, F. and Smith, M.C. (2012) Acute Kidney Injury: A Guide to Diagnosis and Management. American Family Physician, 86, 631-639.

[33] Makris, K. and Spanou, L. (2016) Acute Kidney Injury: Definition, Pathophysiology and Clinical Phenotypes. The Clinical Biochemist Reviews, 37, 85-98.

[34] Tyagi, A. and Aeddula, N.R. (2021) Azotemia. StatPearls Publishing, Treasure Island. https://www.ncbi.nlm.nih.gov/books/NBK538145/

[35] Koratala, A., Bhattacharya, D. and Kazory, A. (2019) Point of Care Renal Ultrasound for the Busy Nephrologist: A Pictorial Review. World Journal of Nephrology, 8, 44-58. https://doi.org/10.5527/wjcc.v8.i3.44

[36] POCUS 101 (2021) Ultrasound Knobology Probes and Modes Made Easy! https://www.pocus101.com/ultrasound-machine-basics-knobology-probes-and-mo des/

[37] Hodhod, A., Capolicchio, J.-P., Jednak, R., El-Sherif, E., El-Doray, A.E.-A. and El-Sherbiny, M. (2016) Evaluation of Urinary Tract Dilation Classification System for Grading Postnatal Hydronephrosis. The Journal of Urology, 195, 725-730. https://doi.org/10.1016/j.juro.2015.10.089

[38] Koratala, A. (2019) The Ultrasound Mimics of Hydronephrosis. Renal Fellow Network.

[39] Khanji, M.Y., Ricci, F., Patel, R.S., Chahal, A.A., Bhattacharyya, G.V., et al. (2020) Special Article-The Role of Hand-Held Ultrasound for Cardiopulmonary Assessment during A Pandemic. Progress in Cardiovascular Diseases, 63, 690-695. https://doi.org/10.1016/j.pcad.2020.07.003

[40] Trinquart, L., Bruno, O., Angeli, M.L., Belghiti, J., Chatellier, G. and Vilgrain, V. (2009) A Hand-Held Ultrasound Machine vs Conventional Ultrasound Machine in the Bedside Assessment of Post-Liver Transplant Patients. European Radiology, 19, 2441-2447. https://doi.org/10.1007/s00330-009-1417-3

[41] Prinz, C. and Voigt, J.-W. (2011) Diagnostic Accuracy of a Hand-Held Ultrasound Scanner in Routine Patients Referred for Echocardiography. Journal of the American Society of Echocardiography, 24, 111-116. https://doi.org/10.1016/j.echo.2010.10.017

[42] Scholten, C., Rosenhek, R., Binder, T., Zehetgruber, M., Maurer, G. and Baumgartner, H. (2005) Hand-Held Miniaturized Cardiac Ultrasound Instruments for Rapid and Effective Bedside Diagnosis and Patient Screening. Journal of Evaluation in Clinical Practice, 11, 67-72. https://doi.org/10.1111/j.1365-2753.2004.00506.x 